\title{
The Cryogenic Enrichment System in Chromatographic Analysis of Noble Gases in Groundwater
}

\author{
J. NAJMAN* AND I. ŚlLIWKA \\ Institute of Nuclear Physics, Polish Academy of Sciences, E. Radzikowskiego 152, 31-342 Kraków, Poland
}

(Received July 20, 2015; in final form July 18, 2016)

The concentration of helium in groundwater may be a good environmental tracer for groundwater dating in hydrogeology. In this work, we present a chromatographic method for simultaneous analysis of helium, neon, and argon in groundwater from a single groundwater sample. Proper use of environmental tracers for dating purposes requires the knowledge of the recharge temperature of the system and the excess air. Both parameters can be determined by measuring the concentration of argon and neon in groundwater. The lowest helium concentration in groundwater is $4.8 \times 10^{-8} \mathrm{~cm}_{\mathrm{STP}}^{3} / \mathrm{g}_{\mathrm{H}_{2} \mathrm{O}}$ at sea level and temperature $10^{\circ} \mathrm{C}$. In view of the deficiency of a suitable detector with a limit of detection for helium at the level of $4.8 \times 10^{-8} \mathrm{~cm}_{\mathrm{STP}}^{3} / \mathrm{g}_{\mathrm{H}_{2} \mathrm{O}}$, the application of the enrichment method is necessary. In this work, the cryogenic method of enrichment with activated charcoal at abated pressure conditions was applied. Helium, neon and argon are analyzed on two gas chromatographs equipped with capillary and packed columns (filled with molecular sieve 5A and activated charcoal) and three thermo-conductive detectors. The chromatographic method was applied to groundwater dating from Kraków and Żarnowiec aquifers. The levels of detection for measurement systems for the tested compounds are: $1.9 \times 10^{-8} \mathrm{~cm}_{\mathrm{STP}}^{3} / \mathrm{cm}^{3}$ for neon, $3.1 \times 10^{-6} \mathrm{~cm}_{\mathrm{STP}}^{3} / \mathrm{cm}^{3}$ for argon, and $1.2 \times 10^{-8} \mathrm{~cm}_{\mathrm{STP}}^{3} / \mathrm{cm}^{3}$ for helium.

DOI: 10.12693/APhysPolA.130.737

PACS/topics: 68.43.-h, 07.20.Mc, 92.40.Kf, 92.40.-t

\section{Introduction}

The helium (He) concentration in groundwater is a fine indicator for groundwater dating in a range from hundreds to tens of thousands of years, and is also used for dating young groundwater [1-4]. The helium concentration in the atmosphere is about $5.24 \mathrm{ppm}$. Surface water in equilibrium with the atmosphere and at the temperature of $20^{\circ} \mathrm{C}$ contains about $8.6 \times 10^{-12} \mathrm{~g}_{\mathrm{He}} / \mathrm{cm}_{\mathrm{H}_{2} \mathrm{O}}^{3}$. The helium concentration can be increased in groundwater as a result of excessive air getting into the groundwater or as a diffusion and accumulation in groundwater helium which is non-atmospheric. This non-atmospheric excessive helium is correlated with the age of the groundwater and is used inter alia for dating $[5,6]$. It can originate from: (a) in situ production in rock material as a result of the presence of radioactive isotopes: ${ }^{238} \mathrm{U},{ }^{235} \mathrm{U}$ and ${ }^{232} \mathrm{Th}$; (b) diffusion release of helium accumulated in sandy grains; (c) outside flux [5]. Applications of helium method, known so far, consisted of ${ }^{4} \mathrm{He}$ concentration measurements using special mass spectrometers [7]. Such measurements unfortunately are very expensive and not available in Poland. This is the reason why this problem was solved by using the more cost effective gas chromatographic (GC) method.

For surface waters in equilibrium with the atmosphere in temperature of $10^{\circ} \mathrm{C}$, the rate of ${ }^{3} \mathrm{He} /{ }^{4} \mathrm{He}$ amounts to $140 \times 10^{-8}$ and is often signified by $R_{A}$. Helium that has originated solely from the Earth crust $\left(R_{c}\right)$

\footnotetext{
* corresponding author; e-mail: Joanna.Najman@ifj.edu.pl
}

should have $R_{c} / R_{A}=0.01$, and helium that originates only from the Earth mantle $\left(R_{m}\right) R_{m} / R_{A}=8$. These datasets show that $\left({ }^{3} \mathrm{He} /{ }^{4} \mathrm{He}\right)_{c}=140 \times 10^{-10}$ and $\left({ }^{3} \mathrm{He} /{ }^{4} \mathrm{He}\right)_{m}=1.1 \times 10^{-5}$, so the highest concentration of ${ }^{3} \mathrm{He}=1.12 \times 10^{-5}{ }^{4} \mathrm{He}$. Measurements of ${ }^{4} \mathrm{He}$ for dating groundwater can be substituted for the measurements of total helium concentration, because concentration of ${ }^{3} \mathrm{He}$ is considerably low and does not exceed $1.0 \times 10^{-5}$ in most cases. However, the lack of measurement of ${ }^{4} \mathrm{He}$ and ${ }^{3} \mathrm{He}$ impossible to conduct other important interpretation, for example, determination the origin of the excess helium in groundwater. The use of helium method (and other dating methods such as $\mathrm{SF}_{6}$ and $\mathrm{CFCs}[8,9]$ ) in hydrogeology for dating purposes requires the knowledge of the recharge temperature of the groundwater system and excess air $[5,10]$. Both parameters can be determined using the neon/argon (Ne/Ar) graphical method [11] which requires the simultaneous measurement of neon $(\mathrm{Ne})$ and argon (Ar) in groundwater. Interpretation of the noble gases concentrations variability can also provide valuable information about the conditions of hydrodynamic systems of studied aquifers. In the Department of Physicochemistry of Ecosystems at the Polish Academy of Sciences, the GC method for measurements of helium, neon and argon from one groundwater sample was developed and is presented in the article.

\section{Materials and methods}

The determination of helium, neon, and argon concentration in groundwater using the developed GC method (Fig. 1) requires [12]: (1) sampling groundwater (from the well) without the contact with atmospheric air, (2) gas extraction from the groundwater sample using 
head-space method [9], (3) analysis of the sample in chromatographic system GC1 which lasts 8 min [13], (4) in the case of low concentration of helium below $14 \times 10^{-8} \mathrm{~cm}_{S T P}^{3} / g_{H_{2} \mathrm{O}}$ (no visible peak of helium in the chromatogram of GC1) analysis of the rest of the sample in gas chromatographic system GC2 (Fig. 1) equipped with a cryogenic sample enrichment system (with activated charcoal) [6].

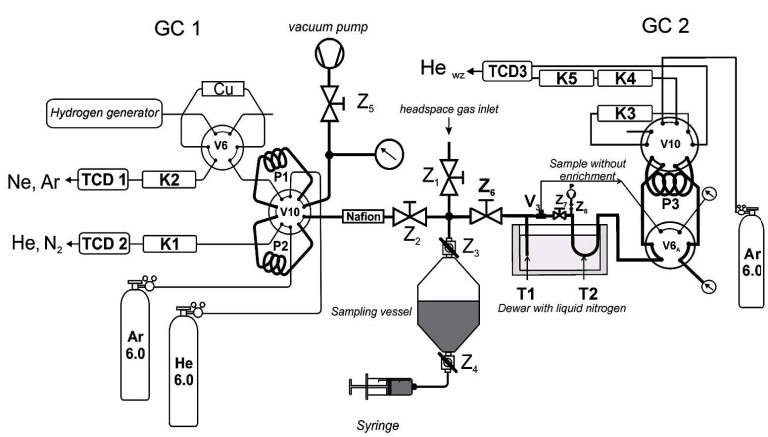

Fig. 1. Schematic layout of a chromatographic system for the simultaneous measurement of $\mathrm{He}, \mathrm{Ar}$, and $\mathrm{Ne}$ in a single groundwater sample ([12], changed).

\subsection{Sampling groundwater without the contact with air}

Currently, the sampling system is adapted to pumped or artesian wells and consists only of copper or steel elements (tubes, valves)

Groundwater samples are taken to the stainless steel vessels of volume equal to $2900 \mathrm{~cm}^{3}$ (Fig. 2), designed in a way that application of head-space method is possible [9]. Wells are sampled under pressure to avoid sample degassing. The vessel has two outlets ending with ball valves $\mathrm{Z} 3, \mathrm{Z} 4$. The valves used allow for easy connection of a vessel with the system of tubes employed to sample groundwater from the well and allow for extraction of gases from a sample in the laboratory.

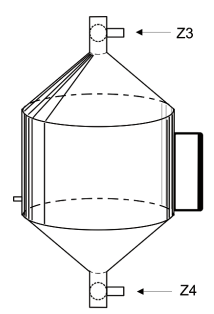

Fig. 2. Measuring vessel [12].

A scheme of the groundwater sampling system is presented in Fig. 3. During sampling, the vessels are flushed with groundwater of volume equal to thirty liters. As noble gases are highly volatile, it is very important to avoid gas exchange between the groundwater sample and the atmosphere during sampling, transport or storage. To control the airtightness of the sampling system during

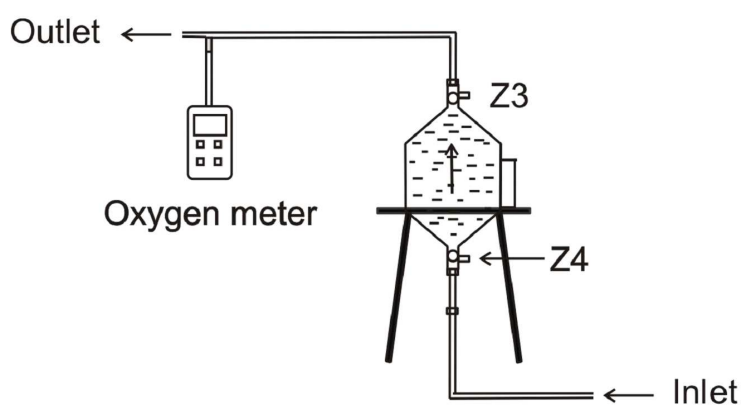

Fig. 3. Scheme of the groundwater sampling system [12].

the sampling, the oxygen concentration in the groundwater is measured. Samples are stored in a laboratory refrigerator at $6{ }^{\circ} \mathrm{C}$. It is recommended that an additional effort be made to analyze them within few days after sampling. Although we verified concentrations of helium, neon, and argon in groundwater samples stored for three weeks, these concentrations were not altered in the margin of measurement uncertainty.

\subsection{Extraction of gases from groundwater samples using the head-space method}

The head-space method [9] of gas extraction from a sample consists of the analysis of gases (Fig. 1) from the space above a groundwater sample enclosed in an airtight vessel. The gaseous sample is analyzed after previously bringing such system (liquid-gas) to the state of thermal equilibrium. In the head-space method it is necessary to perform several steps. The first one is to introduce a gas which does not contain helium, neon, and argon to the measurement vessel filled with a groundwater sample. The gas is brought under pressure to the $\mathrm{Z} 3$ valve (Fig. 1) forcing out water from the vessel through the plastic drain pipe to the syringe. To accelerate establishment of the thermal equilibrium state between gas and liquid phases, the vessel with the created head-space (HS) phase is shaken on the shaker for $30 \mathrm{~min}$. The following gas phase is ready for analysis in the chromatographic system.

\subsection{Description of the GC1 measurement system for} the simultaneous analysis of neon, argon, and helium

A gas sample obtained with the head space method is introduced into the vacuum extraction line, highlighted in Fig. 1 in bold lines. After removal of the water vapor on the Nafion tube, the gas sample fills two dosing loops $\mathrm{P} 1(2 \mathrm{ml})$ and $\mathrm{P} 2(1 \mathrm{ml})$. Analysis of $\mathrm{He}, \mathrm{Ar}$, and $\mathrm{Ne}$ is performed using a Shimadzu GC-17A gas chromatograph equipped with two thermal-conductivity detectors TCD [12]. For the detection of neon and argon, a thermal conductivity detector (TCD1) is used. TCD1 is working with helium 6.0 as the carrier gas, and $30 \mathrm{~m}$ capillary column filled with a molecular sieve 5A (K2 in Fig. 1). In the determination of argon from gas samples using 
gas chromatography, the separation of argon from oxygen presents the biggest problem. This problem can be solved with suitable catalysts that remove oxygen from the analyzed sample [11]. In the developed measuring system, copper oxide $(\mathrm{CuO})$ was used as a catalyst. Periodically, the catalyst was regenerated with hydrogen at a temperature of $200^{\circ} \mathrm{C}$.

For the detection of helium thermal conductivity detector (TCD2), argon 6.0 and capillary column (with a length of $30 \mathrm{~m}$ packed with a molecular sieve 5A (K1 in Fig. 1)) was used.

\subsection{Description of the GC2 measurement system for analysis of helium with sample enrichment system}

In the case of low concentration of helium below $14 \times 10^{-8} \mathrm{~cm}_{\mathrm{STP}}^{3} / \mathrm{g}_{\mathrm{H}_{2} \mathrm{O}}$ (no visible peak of helium in the chromatogram of GC1) the rest of the sample gas is analyzed in gas chromatographic system GC2 (Fig. 1) equipped with a cryogenic sample enrichment system [6].

The analysis of helium in GC2 was performed on the Shimadzu GC-2014 gas chromatograph equipped with a thermal conductivity detector TCD3 and three packed columns K3 $(1.5 \mathrm{~m})$, K4 $(7 \mathrm{~m})$ and $\mathrm{K} 5(2 \mathrm{~m})$ (Fig. 1). Columns K3 and K4 are filled with a molecular sieve 5A [14, 15]. The column K5 is filled with a molecular sieve $5 \mathrm{~A}$ and activated charcoal in a ratio of $1 / 1[16]$. This is done in order to obtain a better separation of the peaks of helium and neon. The system also consists of a dosing loop P3 $\left(10 \mathrm{~cm}^{3}\right)$, the sample enrichment system, and a rotary pump $\mathrm{P}$. The enrichment of the gas sample is made in a trap T2 (Fig. 1) filled with activated charcoal Merck 35-50 mesh adsorbing all gases except helium and neon. They are not adsorbed at liquid nitrogen temperature and remain above the adsorbent. Trap T1 is used to remove from gas sample the water vapor at liquid nitrogen temperature. The sample obtained by extraction using the head-space method after enrichment fills the entire volume from the trap T2 to dosing loop P3 (formerly pumped off). Argon 6.0 (99.9999\%) from Linde Gas works as a carrier gas and the feed gas in detector TCD3. The separated sample of helium and neon in column K5 goes to the detector TCD3. The GC2 system was also adapted to direct gaseous sample analysis by fitting an additional 6 -way $\mathrm{V} 6 \mathrm{~A}$ and 3 -way $\mathrm{V}_{3}$ valves (Fig. 1). The changeover of $\mathrm{V} 6 \mathrm{~A}$ and $\mathrm{V}_{3}$ valves position makes the sample directly filling the dosing loop P3. This provides excellent opportunity to compare results obtained through different methods for one groundwater sample.

\subsection{The cryogenic enrichment method}

The gaseous sample obtained by extraction headspace goes to the system of two traps T1 and T2 (Fig. 4), placed in a vessel with liquid nitrogen. The sample enrichment system consists of a drier T1, T2 trap, valves Z6, Z7, Z8, $\mathrm{V}_{3}$ and rotary vacuum pump $\mathrm{P}$. It also consists of the dosing loop P3, a thermos flask with liquid nitrogen, and the oven. A detailed scheme of the enrichment system is shown in Fig. 4. Prior to analysis, two traps are pumping by a rotary pump $\mathrm{P}$ at $200^{\circ} \mathrm{C}$. The first trap $\mathrm{T} 1$ with a volume $V_{\mathrm{T} 1}=5.5 \mathrm{~cm}^{3}$ is designed to remove water vapor, second T2 with a volume $V_{\mathrm{T} 2}=3.5 \mathrm{~cm}^{3}$, U-shaped, is used for the proper sample enrichment. Z7 valve separates the drier trap T1 from T2 and sample loop, while $\mathrm{Z} 8$ valve separates the vacuum pump $\mathrm{P}$ from the enrichment system. The enrichment of a gas sample on helium content is made in trap T2 filled with $V_{w}=1 \mathrm{~cm}^{3}$ of $35-$ 50 mesh activated carbon from Merck adsorbing all gases except helium and neon. They do not adsorb at liquid nitrogen temperature and remain on the adsorbent.

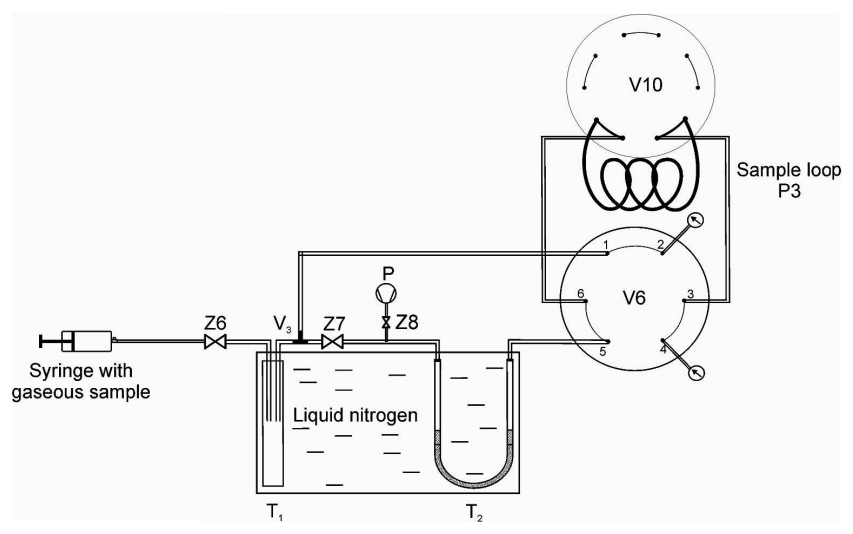

Fig. 4. Scheme of the gas sample enrichment system.

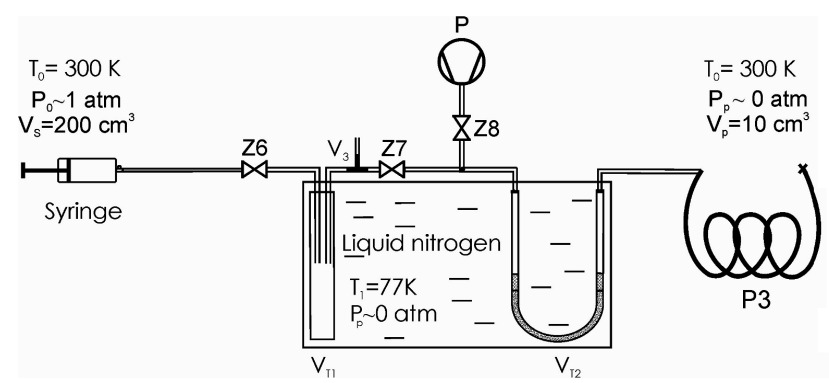

Fig. 5. The state 1 of the enrichment system, wherein the traps T1 and T2, and the sample loop are evacuated.

A description of physical phenomena occurring in the sample enrichment system is shown in Figs. 5 and 6 . In Fig. 5, the state can be seen when the system is evacuated, a charcoal is activated at $200{ }^{\circ} \mathrm{C}$ and prepared for analysis. In this state, the sample gas pressure $P_{0}$ is equal to atmospheric pressure, volume of the gaseous sample is $V_{S}=200 \mathrm{~cm}^{3}$, the pressure in the sample loop P3 and in the traps $\mathrm{T} 1$ and $T 2$ is close to $P_{p} \approx 0$ atm, traps temperature is $77 \mathrm{~K}$. Figure 6 shows the state of the system after the sample enrichment for a period of $20 \mathrm{~min}$, wherein the gas sample has been introduced into the enrichment system at liquid nitrogen temperature $(77 \mathrm{~K})$ and the enrichment process took place. The volume of $\mathrm{V}_{S}$ of the sample in this state is equal to $0 \mathrm{~cm}^{3}$, the pressure $P_{p}$ in the sample loop P3 and in the trap T2 is equal 


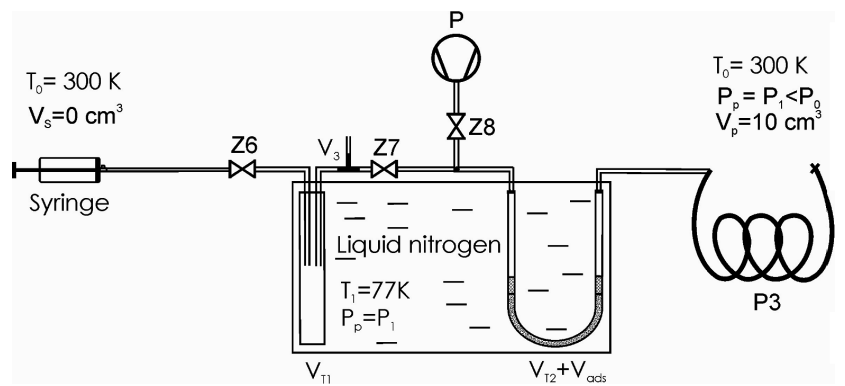

Fig. 6. The state 2 of the enrichment system, wherein the gaseous sample $V_{S}$ fills a volume of a trap T2 and sample loop P3.

to the pressure $P_{1}$ different than zero.

The process of helium enrichment in the gas sample can be described by a factor $\kappa$ which is the ratio of the peaks area of the standard $\left(A_{p} / A_{s t}\right)$ to dispense of gas sample using the enrichment system and with direct injection and the ratio of dispensing volumes $\left(V_{A} / V_{d}\right)$.

Enrichment factor $\kappa$ is defined as follows [6]:

$$
\kappa \stackrel{\text { def }}{=} \frac{A_{p}}{A_{s t}} \cdot \frac{V_{d}}{V_{A}},
$$

where $A_{p}$ - peak area for the helium standard from the analysis in the system using the enrichment method, $A_{s t}$ - peak area for the helium standard from the analysis in the system without the enrichment method, $V_{A}$ volume of dosed gas sample from the analysis in the system using the enrichment method, $V_{d}$ - volume of dosed gas sample from the analysis in the system without the enrichment method.

In order to determine the enrichment factor $\kappa$ for helium, the gaseous sample, of standard with a concentration $C_{s t}=14.9 \mathrm{ppm}$ of helium were dosed ten times using the system of enrichment and without the system. The standard was dosed using a sample loop of volume equal to $10 \mathrm{~cm}^{3}$. Obtained enrichment factor for helium equals to 0.4 indicating that the system of enrichment allows up to eight-fold enrichment of helium.

\subsection{Calibration of the system with gas standards}

The method of calculating the analyzed gas concentrations includes the calculation of the concentration of helium, neon, and argon in the gas phase generated in the measurement vessel, and then calculating the gas concentration in groundwater. For this purpose, it is necessary to calibrate the measuring system in advance with a standard of known concentrations of analyzed gases. The measurement system was calibrated using four standards (from Linde Gas) with the concentrations respectively: (1) $14.9 \mathrm{ppm}$ of $\mathrm{He}\left(\right.$ rest $\mathrm{N}_{2}$ ); (2) $101 \mathrm{ppm}$ of He (rest Ar); (3) $4.951 \mathrm{ppm}$ of $\mathrm{Ne}, 0.6109 \%$ of Ar, $20.255 \%$ of $\mathrm{N}_{2}$ $\left(\right.$ rest $\mathrm{O}_{2}$ ); (4) $4.9 \mathrm{ppm}$ of $\mathrm{Ne}, 0.518 \%$ of $\mathrm{Ar}\left(\right.$ rest $\mathrm{N}_{2}$ ).

To calibrate the system, the above mentioned standards were dosed to the system using sample loops of volumes: $0.5,1,2,3,5$, and $10 \mathrm{~cm}^{3}$. The results of the calibration are shown in Fig. $7 \mathrm{~A}-\mathrm{D}$.

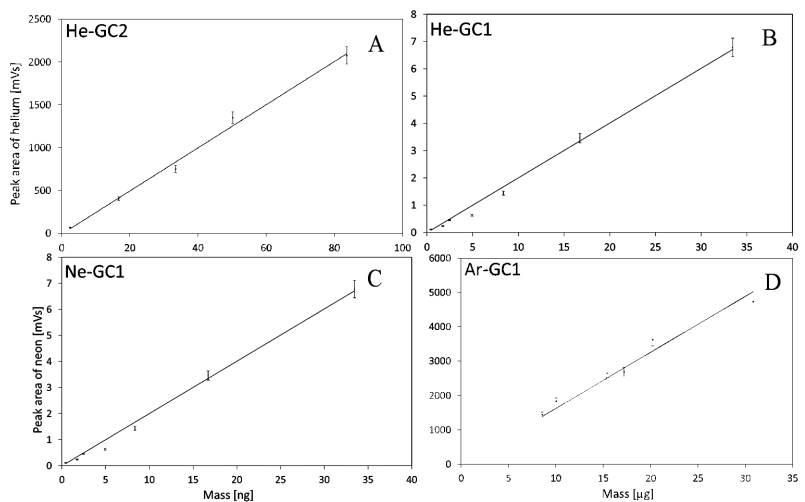

Fig. 7. The calibration curves of TCD detectors: (A) for helium in GC2 (TCD3); (B) for helium in GC1 (TCD2); (C) for neon in GC1 (TCD1); (D) for argon in GC1 (TCD1).

\section{Results of analyzing helium, neon and argon in the GC measurement system}

Examples of helium, neon and argon analysis using developed GC method are shown in Fig. 8. Chromatograms from the gas sample analysis for GC1 are shown in Fig. 8a and $\mathrm{b}$. Chromatograms from the gas sample analysis for GC2 are shown in Fig. 8c and d.
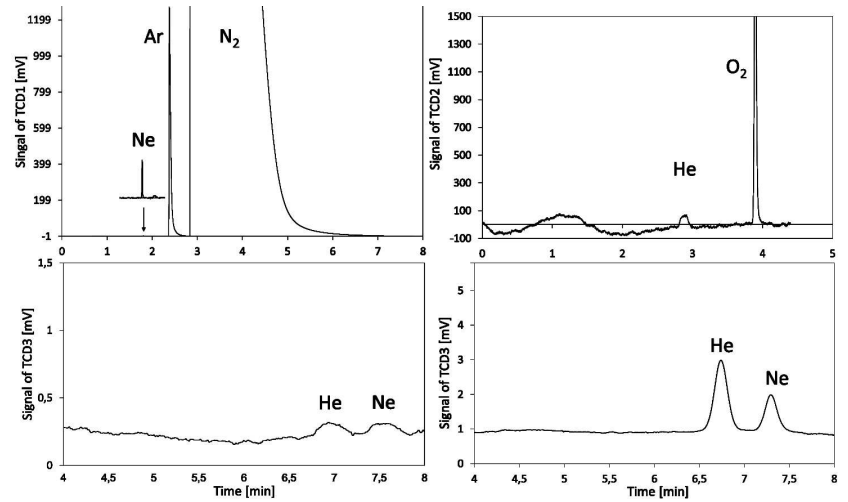

Fig. 8. Examples of helium analysis using developed gas chromatography method: (a) chromatogram from the analysis of $2 \mathrm{~cm}^{3}$ of $\mathrm{Ne}$ and Ar standard (4.9 ppm of $\mathrm{Ne}, 0.518 \%$ of $\mathrm{Ar}$ ); (b) chromatogram from the analysis of $1 \mathrm{~cm}^{3}$ of He standard (101 ppm of $\mathrm{He}$ ); (c) chromatogram from the analysis of $10 \mathrm{~cm}^{3}$ of air sample (5.24 ppm He) without the enrichment system;(d) chromatogram from the analysis of $200 \mathrm{~cm}^{3}$ of air $(5.24 \mathrm{ppm}$ of $\mathrm{He}, 18.18 \mathrm{ppm}$ of $\mathrm{Ne}$ ) using the enrichment system.

Developed in Institute of Nuclear Physics of PAS (IFJ PAN), Kraków, the gas chromatographic method after validation was tested with measurements of groundwater from the area of Kraków. The selected well was earlier studied using mass spectrometric (MS) method by Zuber et al. [17]. The measurement results for GC method and MS method (with uncertainty $2 \%$ for ${ }^{4} \mathrm{He}, 1.5 \%$ for $\mathrm{Ne}$ and $1 \%$ for Ar) are shown in Table I. Knowledge of Ne 
and Ar concentrations in groundwater from the area of Kraków allowed us to calculate recharge noble gas temperature (NGT) and excess air, shown also in Table I. With the knowledge of these two parameters, it was possible to calculate the helium components in groundwater. These components are helium concentration result- ing from the thermodynamic equilibrium between the surface water and the atmosphere $\left(\mathrm{He}_{e q}\right)$, resulting from the excess air $\left(\mathrm{He}_{e x a}\right)$ and excess helium $\left(\mathrm{He}_{\text {exc }}\right)$ resulting from the age of groundwater. Calculated helium components are also shown in Table I.

TABLE I

Calculated recharge temperature and the excess air for groundwater from the area of Inwalidów sq. in Kraków, and the components of helium for GC and MS methods. He - measured concentration of helium in groundwater; $\mathrm{He}_{\text {exa }}$ - helium component resulting from the presence of excess air in the groundwater; $\mathrm{He}_{e q}$ - helium component resulting from the thermodynamic equilibrium between the surface water and the atmosphere; $\mathrm{He}_{\text {exc }}$ - excess helium resulting from the age of the groundwater (the residence time of groundwater).

\begin{tabular}{|c|c|c|c|c|c|c|c|c|}
\hline \multirow{2}{*}{ Well } & $\mathrm{Ne}$ & $\mathrm{Ar}$ & \multirow{2}{*}{$\begin{array}{l}\text { NGT } \\
{\left[{ }^{\circ} \mathrm{C}\right]}\end{array}$} & \multirow{2}{*}{$\begin{array}{c}\text { Excess air } \\
{\left[\mathrm{cm}^{3} / \mathrm{L}\right]}\end{array}$} & $\mathrm{He}$ & $\overline{\mathrm{He}_{e x a}}$ & $\mathrm{He}_{e q}$ & $\mathrm{He}_{e x c}$ \\
\hline & \multicolumn{2}{|c|}{$10^{-7} \mathrm{~cm}_{\mathrm{STP}}^{3} / \mathrm{cm}^{3}$} & & & \multicolumn{4}{|c|}{$10^{-8} \mathrm{~cm}_{\mathrm{STP}}^{3} / \mathrm{cm}^{3}$} \\
\hline $\mathrm{GC}$ & $2.49 \pm 0.13$ & $4.44 \pm 0.22$ & $5.2 \pm 1.2$ & $2.47 \pm 0.6$ & $165 \pm 12$ & $1.29 \pm 0.2$ & $4650 \pm 100$ & $159.1 \pm 12$ \\
\hline $\begin{array}{l}17] \\
17\end{array}$ & 2.726 & 4643 & 46 & - & 179.9 & - & - & 166 \\
\hline MS & 2.553 & 4448 & & & 164 & & & \\
\hline
\end{tabular}

The obtained concentration of excess helium for the Inwalidów Square aquifer indicate the glacial age of groundwater with the residence time greater than about 10,000 years [5]. Additionally NGT at the level of about $5{ }^{\circ} \mathrm{C}$ also indicates the glacial age of groundwater. The verification (Table I) showed compliance of measurements performed in the Institute of Nuclear Physics using GC method with measurements using MS method in the margin of measurement uncertainty.

Currently, measurements of helium, neon, and argon concentrations in groundwater from the area of Żarnowiec are conducted. They are performed in order to assess the resistance of the hydrogeological system to anthropogenic pollution. The resistance is usually correlated with the age of groundwater. The greater the age, the aquifer is usually more resistant to anthropogenic pollution. The results of measurements of samples taken in May 2013 are shown in Table II. They show received concentrations of neon, argon, and helium for the groundwater of the Żarnowiec region and calculated NGT temperatures, excess air, which made it possible to correct the concentration of helium $\left(\mathrm{He}_{\text {exc }}\right.$ - Table III) [5].

TABLE II

The results of neon, argon and helium measurements in groundwater from the area of Żarnowiec in 2013 along with the calculated excess air and NGT.

\begin{tabular}{c|c|c|c|c|c}
\hline \hline \multirow{2}{*}{ Location } & $\mathrm{Ne}$ & $\mathrm{Ar}$ & $\mathrm{He}$ & \multirow{2}{*}{$\begin{array}{c}\mathrm{NGT} \\
{\left[{ }^{\circ} \mathrm{C}\right]}\end{array}$} & $\begin{array}{c}\text { Ex. air } \\
{\left[\mathrm{cm}^{3} / \mathrm{L}\right]}\end{array}$ \\
\cline { 2 - 4 } & \multicolumn{2}{|c|}{$\left[\times 10^{-8} \mathrm{~cm}_{\mathrm{STP}}^{3} / \mathrm{cm}^{3}\right]$} & & $7.4 \pm 1$ & $1.2 \pm 0.4$ \\
\hline Karlikowo & $22.7 \pm 1.2$ & $4180 \pm 230$ & $6.23 \pm 1.9$ & 7.4 & \\
\hline Sobieńczyce & $23.0 \pm 1.3$ & $4020 \pm 200$ & $6.20 \pm 1.9$ & $9.5 \pm 1.1$ & $1.6 \pm 0.5$ \\
\hline Lubocino & $22.5 \pm 1.2$ & $4020 \pm 200$ & $5.38 \pm 1.6$ & $8.7 \pm 1.1$ & $1.5 \pm 0.6$ \\
\hline Tyłowo & $23.0 \pm 1.3$ & $4090 \pm 200$ & $6.42 \pm 2.0$ & $9.0 \pm 1$ & $1.5 \pm 0.5$
\end{tabular}

TABLE III

The results of obtained helium concentration and calculated components of helium in groundwater from the Żarnowiec area in 2013

\begin{tabular}{c|c|c|c|c}
\hline \hline \multirow{2}{*}{ Location } & $\mathrm{He}$ & $\mathrm{He}_{\text {exa }}$ & $\mathrm{He}_{\text {eq }}$ & $\mathrm{He}_{\text {exc }}$ \\
\cline { 2 - 5 } & \multicolumn{4}{|c}{$\left[\times 10^{-8} \mathrm{~cm}_{\mathrm{STP}}^{3} / \mathrm{cm}^{3}\right]$} \\
\hline Karlikowo & $6.23 \pm 1.9$ & $0.63 \pm 0.21$ & $4.69 \pm 0.2$ & $\mathbf{0 . 9 1} \pm \mathbf{1 . 9}$ \\
\hline Sobieńczyce & $6.20 \pm 1.9$ & $0.84 \pm 0.26$ & $4.65 \pm 0.2$ & $\mathbf{0 . 7 1} \pm \mathbf{1 . 9}$ \\
\hline Lubocino & $5.38 \pm 1.6$ & $0.68 \pm 0.31$ & $4.65 \pm 0.2$ & $\mathbf{0 . 0 3} \pm \mathbf{1 . 6}$ \\
\hline Tyłowo & $6.42 \pm 2.0$ & $0.79 \pm 0.26$ & $4.64 \pm 0.2$ & $\mathbf{0 . 9 9} \pm \mathbf{2 . 0}$
\end{tabular}

The results indicate that the examined groundwater are young (several decades), from a contemporary recharge. The lowest concentration of excess helium for Lubocino aquifer shows that these groundwater is the youngest, and the oldest groundwater is from Tyłowo with the highest concentration of excess helium. Also the NGT indicates the Holocene (contemporary) age of groundwater. More detailed interpretation will be possible after the next round of the measurement made in autumn 2016. Usually groundwater dating is often complemented by detailed hydrogeochemical description of studied aquifers $[17,18]$. Such interpretation will be also conducted in the future studies.

\section{Conclusions}

The gas chromatographic system described here can be used to measure the concentration of helium, neon, and argon in the groundwater in a wide range of concentrations. LOD detection levels obtained for the individual compounds in groundwater samples of volume of $2900 \mathrm{~cm}^{3}$, from which helium, neon, and argon were extracted into the head space phase volume 
of $200 \mathrm{~cm}^{3}$, amounts to: $1.9 \times 10^{-8} \mathrm{~cm}_{\mathrm{STP}}^{3} / \mathrm{cm}^{3}$ for $\mathrm{Ne}$, $3.1 \times 10^{-6} \mathrm{~cm}_{\mathrm{STP}}^{3} / \mathrm{cm}^{3}$ for Ar, $14 \times 10^{-8} \mathrm{~cm}_{\mathrm{STP}}^{3} / \mathrm{cm}^{3}$ for He in the system without enrichment system (GC1) and $1.2 \times 10^{-8} \mathrm{~cm}_{\mathrm{STP}}^{3} / \mathrm{cm}^{3}$ for He in the system with sample enrichment (GC2). Obtained detection levels also allow the determination of helium, neon, and argon in surface waters. The concentrations of these gases in groundwater may not be lower than in surface waters. The developed chromatographic system was used to determine the age of groundwater recharged from Holocene to the glacial period. The obtained measurement uncertainty of the total helium concentration in groundwater is in the range from $7 \%$ for glacial to $30 \%$ for modern groundwater. This involves a greater uncertainty to determine the age of modern groundwater. Nevertheless the interpretation of helium concentration variability can also provide valuable information about the conditions of hydrodynamic systems of studied aquifers.

\section{Acknowledgments}

Work performed within the strategic research project "Technologies supporting the development of safe nuclear power" financed by the National Centre for Research and Development (NCBiR). Research Task "Development of methods to assure nuclear safety and radiation protection for current and future needs of nuclear power plants", contract No. SP/J/6/143339/11. This work was also supported by grant No. N N525 348838 from the National Science Centre.

\section{References}

[1] J.N. Andrews, Isotopes of noble gases as tracers in environmental studies, Mechanisms for noble gases dissolution by groundwaters, International Atomic Energy Agency, Vienna 1992, p. 87.
[2] M.C. Castro, M. Stute, P. Schlosser, Appl. Geochem. 15, 1137 (2000).

[3] W. Aeschbach-Hertig, F. Peeters, U. Beyerle, K. Kipfer, Water Resour. Res. 35, 2779 (1999).

[4] U. Beyerle, Ph.D. Thesis, The Swiss Federal Institute of Technology, Zürich 1999.

[5] A. Zuber, W. Ciężkowski, K. Różański, Methodological Guide, The Publishing House of Wrocław University of Technology, Wrocław 2007.

[6] J. Najman, Ph.D. Thesis, Institute of Nuclear Physics, Polish Academy of Sciences, Kraków 2008.

[7] U. Beyerle, W. Aeschbach-Hwertig, D.M. Imboden, H. Baur, T. Graf, R. Kipfer, Environm. Sci. Technol. 34, 2042 (2000).

[8] J. Bielewski, I. Śliwka, Acta Phys. Pol. A 125, 895 (2014).

[9] I. Śliwka, J. Lasa, Chem. Anal. (Warsaw) 45, 59 (2000).

[10] J. Lasa, P. Mochalski, J. Pusz, J. Chromatogr. A 1035, 261 (2004).

[11] P. Mochalski, Ph.D. Thesis, Institute of Nuclear Physics, Polish Academy of Sciences, Kraków 2003.

[12] J. Najman, I. Śliwka, PIG Biuletyn 456/2, 419 (2013), (in Polish).

[13] A. Żurek, P. Mochalski, Geologia - Kwartalnik AGH 36, 135 (2010), (in Polish).

[14] H. Ogino, Y. Aomura, Anal. Chem. 61, 2237 (1989).

[15] H. Ogino, Y. Aomura, T. Seki, Anal. Chem. 63 , 1376 (1991).

[16] E. Zieliński, Chem. Anal. 6, 787 (1961).

[17] A. Zuber, S.M. Weise, J. Motyka, K. Osenbrück, K. Różański, J. Hydrol. 286, 87 (2004).

[18] T. Kotowski, M. Kachnic, Environm. Earth Sci. $\mathbf{7 5}$, 192 (2016). 